\title{
[11]
}

\section{Ilongot Visiting:}

\section{Social Grace and the \\ Rhythms of Everyday Life}

\author{
Renato Rosaldo
}

Why do rituals never begin on time? In casual conversation an anthropologist colleague half-seriously, half-jokingly elevated this fieldwork anxiety into a pressing theoretical issue. Ethnography's major puzzle, she said, is to understand how natives can figure out when their own rituals are about to begin.

When anthropologists speak informally about the pleasures and hardships of fieldwork, they often reflect on the liberation and bafflement of abandoning clock-time for quite different tempos of life. In some versions the people are habitually late. In others, they have a different sense of time. In yet others, they have no sense of time at all. Yet, for all the work on the cultural construction of time, little has been written on the tempo of everyday life in other cultures. Evidently, a paramount reality of other people's daily lives has eluded the ethnographer's grasp.

Ethnographers' sentiments probably echo feelings learned closer to home. The English labor historian E. P. Thompson has described the sense of "time-discipline" that appears so natural in Anglo-American society as the outcome of a protracted historical struggle. Thompson succinctly states his argument as follows: "In all these ways-by the division of labour; the supervision of labour; fines; bells and clocks; money incentives; preaching and schoolings; the suppression of fairs and sports-new labour habits were formed, and a new time-discipline 


\section{Renato Rosaldo}

was imposed" (1967: 90). Those in our society who fail to conform with the painfully imposed "time-discipline" are commonly described as living by C.P.T., Indian Time, or Mexican Time. To make my own position clear, I should hasten to say that my having known Mexican Time from the inside has not kept me from having experienced the ethnographer's dilemma of being just plain perplexed about when ceremonial events in other cultures were about to begin.

The tempo of social being I shall attempt to characterize in this essay usually has been described by its absences, or more precisely, by contrast with its supposed opposite. "We" have "time-discipline," and "they" have, well, something else (or, as we say these days, Otherness). The former quality of time can be described in relation to cultural artifacts, such as clocks, calendars, appointment books, and the like. More significantly, it can be understood in connection with capitalists' desire to discipline and synchronize the labor force, rationalizing production and maximizing profits, but probably not enhancing the quality of life. Certainly this is the drift of the persuasive analyses put forth by E. P. Thompson, and before him, Max Weber.

Max Weber made the very qualities he studied, discipline and rationalization, appear strange by contrasting them with what he called traditionalism. He illustrated his argument with a hypothetical case in which the employer, who pays piece-rates, tries to speed up the labor process by increasing the rates. The employer's move produces a clash between work discipline and traditionalism, which Weber explains in the following terms:

But a peculiar difficulty has been met with surprising frequency: raising the piece-rates has often had the result that not more but less has been accomplished in the same time, because the worker reacted to the increase not by increasing but by decreasing the amount of his work. A man, for instance, who at the rate of 1 mark per acre mowed 21/2acres per day and earned $2 \frac{1}{2} 2$ marks, when the rate was raised to 1.25 marks per acre mowed, not 3 acres, as he might easily have done, thus earning 3.75 marks, but only 2 acres, so that he could still earn the $2 \frac{1}{2}$ marks to which he was accustomed. The opportunity of earning more was less attractive than that of working less. He did not ask: how much can I earn in a day if I do as much work as possible? but: how much must I work in order to earn the wage, $2 \frac{1}{2} 2$ marks, which I earned before and which takes care of my traditional needs? This is an example of what is here meant by traditionalism. A man does not "by nature" wish to earn more and more money, but simply to live as he is accustomed to live 
and to earn as much as is necessary for that purpose. [Weber 1958: $59-60]$

Weber argues that, although "we" assume that people will earn as much as possible in a day, in fact, such behavior is historically and culturally peculiar, and requires further investigation. In making capitalism appear strange, and hence demand explanation, he follows the technique of negative characterization, and makes traditionalism a residual category, more a matter of human nature than an appropriate subject for social analysis. In analytical terms, traditionalism occupies an empty space.

Although ethnographers have made their project the comprehension of traditionalisms, they have not escaped the problem of characterizing the tempo of social life in "traditional" societies more through absences than in positive terms. The anthropological linguist Susan Philips, for example, has called attention to the quality of time I should like to explore. In a fine paper called "Warm Springs 'Indian Time,' " Philips correctly criticizes ethnographic writings for reducing time to segmentation and sequencing. Her analytical goal is to broaden the range of temporal phenomena under study. Her point of departure is that Indian Time appears primarily when non-Indians attend or participate in Indian events: "They [non-Indians] try to learn from Indians at what time the event will begin. Often the person questioned will say he doesn't know, but if pressed, he may give a specific time-e.g., 8 P.M. or 'some time after 9.' The non-Indians will arrive at that time, only to find that 'nothing is happening' yet, and no one seems to know when something will happen. They may wait anywhere from twenty minutes to several hours before the event 'begins" (Philips 1974: 94). Philips's analysis of Indian Time concentrates on a series of social factors that produce variability and indeterminacy in the timing of ceremonial events. Her factors include: whether individuals commit themselves to participate, the degree of interdependence among actors, the number of participants needed for an event to take place, and whether the number of repetitions of particular actions is preset or open-ended. Indian Time thus reaches its maximum with: absence of commitment to participate, high interdependence among actors, an indeterminate number of actors needed, and open-ended repetitions of particular actions.

By identifying the sources of indeterminacy Philips has gone partway along the path I wish to follow. My analysis begins where hers leaves 
off. Instead of concluding with the identification of sources of indeterminacy, I shall start by suggesting that they constitute a social space within which creativity can flourish. In my view optionality, variability, and unpredictability produce positive qualities of social being rather than negative zones of analytically empty randomness. Far from being devoid of positive content (presumably because of not being rulegoverned), indeterminacy enables a culturally valued quality of human relations where one can follow impulses, change directions, and coordinate with other people. In other words, social unpredictability has its distinctive tempo, and it permits people to develop timing, coordination, and a knack for responding to contingencies. These qualities constitute social grace, which in turn enables an attentive and gifted person to enjoy and be effective in the interpersonal politics of everyday life.

I shall argue that, among the Ilongots of northern Luzon, Philippines, zones of indeterminacy, particularly in social visits, promote a human capacity for improvisation in response to the unexpected, and this very capacity can be celebrated as a cultural value. For the moment, however, let me follow Ilongot decorum, as this essay in its presentation imitates its subject matter, by approaching the topic of visiting gradually. As a first step, the Ilongots and their notion of visiting require more extended introduction.

The Ilongots are a group of some 3,500 hunter-horticulturalists who reside in an upland region some ninety miles north of Manila in Luzon, Philippines. They cultivate rice, root crops, and vegetables in rainfed gardens, and they fish and hunt wild pigs and deer. Local groups comprise roughly forty to sixty persons who reside in four to eight dispersed households. Postmarital residence is uxorilocal, kinship is cognatic, and putative descent defines predominantly territorial aggregates called bertan. Head-hunting has long been central in defining the group's cultural identity.

\section{Ilongot Visiting}

Visiting defines and displays the qualities of Ilongot social relations even more centrally than the kinship system. My field journal is simply laced with the arrivals and departures that make up the fabric of everyday life. During some six months of 1969 , for example, I recorded 
the number of people who slept overnight in the home where Michelle Rosaldo and I resided. In that period our household of fourteen permanent members had a low of six and a high of thirty-six people sleeping overnight. The totals for a representative sequence of days ran as follows: $14,17,8,25,16$. In addition to their brute frequency, visits are a staple of ordinary conversation. They are frequently talked about, both as noteworthy events in themselves and because they bring guests who provide news about other people and places. Here the key term is beita, referring at once to a kind of speech, small talk (as opposed, for example, to oratory or storytelling), and to its content: a noteworthy item or news.

Visits, or at any rate the practices Ilongots call ba-at, occur between households of different local groups, rather than within a single local group. People, of course, do drop by to chat or borrow things from other homes within their own local group, but that is not called ba-at. People can visit simply to visit, or to trade, or to borrow, or to court, or to plan a raid; they can be invited to lend their labor for housebuilding, pollarding, planting, or harvesting; they can come to support family members afflicted by serious illness; they can arrive to participate in meetings about bridewealth or local conflicts. Visits can, of course, have multiple purposes, carried out simultaneously, in sequence, or both. A visit can also begin as one thing and turn into something quite different. The casual visitor, for example, can be enlisted to hunt, or the young man who came to help pollard can initiate a courtship, or be obliged to stay on during an uncle's illness.

Marked by open-endedness, visiting often serves as a metonym for social life. In describing their past lives, for example, Ilongots speak of walking on paths that meander, like the courses of streams they follow, in ways that cannot be foreseen. In depicting residential moves, they talk about a coordinated unfolding among agents at once autonomous and accountable to one another. Ilongot visiting, in such contexts, comprises a concrete exemplar of forms of social life marked by mutually adjusted action and an openness to uncertain futures. Visits are improvised, made up as people go along; and social grace, a culturally valued quality of human intelligence, consists of one's responsiveness to whims, desires, and contingencies, whether these emanate from one's own heart or from those of one's partners in action. 


\section{Typifications of Arrival Scenes}

When asked to describe a visit from beginning to end, Ilongots started with the host's account of the guest's arrival, rather than with the latter's departure from home. Ilongots say that when a visitor approaches the house hosts and guests alike neither speak nor make any other noise. Silence is the only form of greeting.

Tukbaw said, "If you talk, the others will think you're talking about them. The host [pan-abung, house owner] should speak first. That person can say a number of things, like, "Are you people from there well?’ If we just talk abruptly, people take it badly.”

Tukbaw's sister-in-law Sawad said that visitors do not speak first because they wait "for their sweat to sink in, for their heart [rinawa] to stretch in happiness [ruyuk]. The host then asks, 'Are you people from there well?" "Visitors speak first only if there is urgent news, like the incipient arrival of soldiers or enemy Ilongot raiders. Otherwise, Sawad elaborated, the visitor "simply waits to be fed."

Talikaw said, "We hush up the kids because they are too noisy for our visitors." When visitors arrive, he said, "We give them betel quids. We go to pound rice because they are hungry. When they finish eating we ask for their news [beita]. We ask, 'Are you people from there well?" "

A cognitive anthropologist could readily rewrite Ilongot typifications of arrival scenes in the form of culturally appropriate expectations. These expectations have comprised the evidentiary basis of cultural description for ethnoscientists, such as Charles Frake (author of the pertinent classic essays "How to Ask for a Drink in Subanun" and "How to Enter a Yakan House") who has depicted his project as follows:

This conception of a cultural description implies that an ethnography should be a theory of cultural behavior in a particular society, the adequacy of which is to be evaluated by the ability of a stranger to the culture (who may be the ethnographer) to use the ethnography's statements as instructions for appropriately anticipating the scenes of the society. I say "appropriately anticipate" rather than "predict" because a failure of an ethnographic statement to predict correctly does not necessarily imply descriptive inadequacy as long as the members of the described society are as surprised by the failure as is the ethnographer. The test of descriptive adequacy must always refer to informants' interpretations of events, not simply to the occurrence of events. [1980a: 145] 
Cultural typifications thus are understood as distillations of past experience that allow natives and ethnographers to anticipate (but not predict) what will happen during future arrival scenes. Viewed in this manner, Ilongot arrival scenes could be segmented into the following phases: (1) the proper greeting of silence; (2) the hosts give their guests betel quids and food; and (3) the hosts ask the guests for their news, saying, "Are you people from there well?" Such typifications better enable ethnographers and natives alike to understand how variations in the actual enactment of these scenes can be interpreted (in relation to a standard code) as perfunctory, clumsy, angry, formal, proper, or graceful (Frake 1980b: 214). Yet the inclination of cognitive anthropology has been to delineate the code and ignore the actual performances, whether perfunctory or graceful.

I shall return to these arrival scenes with a view to exploring the insight yielded by moving from the code of cultural expectations to the social qualities at play in actual practices. The analysis of typifications, I shall argue, is but a point of departure, and by itself says little about the qualities of social relations displayed and created in the context of arrivals. For the time being, however, let us move one step at a time and continue to mimic the meandering path of visitors.

\section{How I Registered Arrivals}

My field journals are filled with reports on (and accounts of discussions about) the comings and goings of visitors and the news brought by them. Visits were intricately woven into the fabric of daily life. Indeed $b a-a t$ soon became a distinct ethnographic category entered on four-by-six cards. A typical early entry runs as follows: "Lapur stayed with his brother-in-law. He spent three nights."

When I wrote my entries on visits it did not occur to me that I was following a conventional form often found in smalltown newspapers. The Listowel Banner from western Ontario, Canada, for example, carries a regular Personals section with about thirty weekly entries on such transitions as deaths, births, weddings, illnesses, and visits. The vast majority of these entries, however, concern visits. The following are representative examples of such entries (all from the September 26,1984 , issue, p. 16):

-Mrs. Goldie Thompson and Mrs. Cathy Cahill of Toronto spent a few days with Mr. and Mrs. George Greer of Holland Centre. 
- Mr. and Mrs. Lang Vogan, RR 2, Wroxeter, have returned home following a nine-day holiday trip to Cape Cod. The local couple travelled by bus, crossing into the United States at Niagara Falls. Mr. Vogan notes that it was raining as they left Listowel and raining as they returned, but the sun shone every day while they were away on their trip. They also found the leaves were in vivid colors as they made the return journey.

-Recent visitors with Mrs. Margaret Hawksbee included Mr. and Mrs. Adam Hackett of Vancouver, B.C., Miss Lillian Hackett of Mitchell, Canon and Mrs. C. F. Heathcote of Burlington, and Mr. and Mrs. Harvey Bride of Don Mills.

My entries and The Listowel Banner's resemble one another in being cultural forms that register visits as bits of news. Not unlike Ilongot typifications, these news items are more often marked by arrivals than departures. Mr. and Mrs. Lane Vogan, for example, become newsworthy, not as they depart, but after they return from their sunny vacation in Cape Cod.

\section{The Web of Visits}

When entries on "visits" were juxtaposed in a string, however, they began to tell a different story. Compiled over a period of days, visits (both actual arrivals and news brought from elsewhere) revealed the fluid intricacies of changing plans. Such shifts of trajectory involved complex judgements about myriad contingencies and unfolding patterns of coordination among individuals.

Coordination among autonomous individuals requires a particularly high degree of flexibility and responsiveness because of cultural notions that make it difficult to predict another's conduct. Ilongots can try to persuade their fellow humans to do as they wish, but they cannot simply tell them what to do. Culturally speaking, they simply do not know what is inside another's heart (rinawa) unless that person speaks and reveals it. Michelle Rosaldo paraphrased Ilongot talk on the matter as follows: "We cannot see the hearts of others; we hear words spoken by strangers but fear that these come only from the surface, not from the inner motions of their hearts" (1980: 43). She elaborates in this manner: "Ilongots speak of 'hearts,' then, not to explain behavior by reference to character, motives, or a well-imaged personality, but to indicate those aspects of the self that can be alienated-or engaged- 
in social interaction. Through talk of hearts, Ilongots characterize the relation between the self and its situation, in terms of whether hearts are closed or open, light or heavy, itching or at ease. What matters in such talk is not 'psychology' as we understand it, but the 'passions' generated in a self that can always be in conflict with its environment" (1980: 43). Individual actions, rather than forming larger patterns that reveal or emanate from more global entities resembling our notion of character, are shaped by the play of relatively discrete passions.

Once, for example, Insan visited another group to swear a peacekeeping oath by salt (sanctioned by the notion that, like salt in water, violators will dissolve in death); a young man in their party deliberately did not hold the salt because he had treachery in his heart. Years later Insan told me that he had had no inkling of the young man's designs because "when we left that time, he [the young man] did not tell us what was in his heart." Insan surmised that the young man's heart must have said (to himself): "I'm surveying the way I'm going to walk when I go on a head-hunting raid against these Butag people." Insan did not learn what was in his companion's heart until it was too late. When Insan's paternal grandfather later died of a gunshot wound, the seeming accident was attributed to the violated oath (R. Rosaldo 1980: 66-79).

In order to illustrate the meandering pattern of coordination in Ilongot visiting I have summarized and pieced together the following relevant entries from my four-by-six cards of 1974:

-Nov. 3: Two young boys arrived at night from Pengegyaben. Their host Tepeg immediately (without a period of silence) asked, "Is something wrong? Is somebody sick?" Tepeg explained that he blurted his questions because the young boys' nocturnal arrival appeared to mean that something was wrong. His eldest son, Keran, was in Pengegyaben at the time.

-Nov. 4: A visitor arrived and told his first cousin Dilap that his wife's return from Keradengan would be delayed because their children were ill. The two cousins said they would hunt together, and then go on to meet the wife and ailing children.

-Nov. 4: Kangat sneezed (a bad omen) as he was about to go and carry home his brother-in-law (who was incapacitated from snakebite). He did not go that day.

-Nov. 5: News arrived that a green viper bit Tepeg's son, Keran, as he started on the trail home.

-Nov. 9: The two cousins set off to hunt, but Dilap returned without 


\section{Renato Rosaldo}

seeing his wife and ailing children because his house-mates and neighbors had gone to distant evangelical services, leaving nobody else home to feed the pigs.

-Nov. 12: Dilap's wife and children arrived, along with others, including Keran. The boy's mother had worried because news had come that her son was going to arrive two days sooner than he did.

My field journal conveys the mood surrounding the group's arrival: "Then, close to dusk, people got all excited; the people from Pengegyaben are here; they saw them walking by Asibenglan-we've been eager for their arrival. They came across the river looking all dressed up and pretty, Ilongot fashion. Keran was walking with a cane [because of his snakebite]; his uncle was across the river, drinking, and would come; his cousin wasn't clear on when we were going to Pengegyaben." A young woman who arrived with the group said she would stay one day and then guide me and Shelly to Pengegyaben, near her place. People in our household asked the young woman to stay overnight and help in the garden.

-Nov. 14: The young woman spent the night at a house downstream, but she still did not return home because it was raining too hard today.

-Nov. 15: We walked to Pengegyaben with the young woman.

Strung together, the entries tell about how plans changed in coordination with other people. Ever flexible and shifting, the visitors have developed a fluid responsiveness to the contingencies of everyday life. By their very nature, of course, contingencies cannot be listed as a finite complete set because as yet unlisted items will always come up as life goes on. In the two-week period reviewed above the contingencies included: sickness, snakebite, rain, gardening, hunting, evangelical services, pig-feeding, and sneezing.

Comparable forms of responsiveness have been vividly depicted for Athabascan hunters. Hugh Brody has described how their decision making takes account of multiple factors in this manner:

To make a good, wise, sensible hunting choice is to accept the interconnection of all possible factors, and avoids the mistake of seeking rationally to focus on any one consideration that is held as primary. What is more, the decision is taken in the doing; there is no step or pause between theory and practice. As a consequence, the decisionlike the action from which it is inseparable-is always alterable (and 
therefore may not properly even be termed a decision). The hunter moves in a chosen direction; but, highly sensitive to so many shifting considerations, he is always ready to change his direction. [1982: 37]

Not unlike Ilongots, these hunters make synoptic judgments informed by sensitivity, responsiveness, and flexibility. Planning, schedules, and time-discipline indeed are at odds with such an open-ended quality of action.

Ilongot visiting shares this quality of open-endedness. Openendedness has positive content in that it enables a social capacity to improvise and respond creatively to life's contingencies. It is precisely this capacity, social grace and a sense of timing, that Ilongots so esteem as a cultural value (R. Rosaldo 1986).

\section{A Man Who Could Not Sleep}

Lest it appear that social grace never fails Ilongots, the case of Kama from Butag is especially pertinent. Kama was from a distant group that had just celebrated an initial covenant, to make amends for past beheadings, with the Kakidugen people. Much to everybody's surprise, Kama appeared as a visitor in our house very shortly after the preliminary settlement.

He arrived, looking fresh, bold in his carriage, and dressed in his finest garb. As Ilongots usually do on formal visits, he had stopped near the house at a stream, where he rested, washed, groomed, and put on his body adornment. My companions admired both his elegant dress and his remarkable courage. His arrival proceeded thus: "In the early afternoon of February 17, Kama and his companion entered the house in silence and sat down. Without a word Tukbaw prepared a betel quid and, as he placed it in my hand, whispered that I should enhance the formality of the occasion. Following my 'brother's' wishes, I walked in measured steps across the room and, with my left arm bent horizontally before me, I squatted and, moving in slow motion, handed Kama the quid with my right hand" (R. Rosaldo 1980: 1034). The silence and slow decorum marked an occasion of high formality. The hosts and guests told stories of settlers and began to discuss the return covenant through the afternoon and on into the evening.

After Kama left the next morning, his hosts began to talk in awed tones about their visitor. They spoke of his bodily elegance, how he 
carried himself and his fine adornment. His decorations had cowrie shells, thin brass wire, white horsehair, boars' fangs, and a tall black feather; they adorned his waist, calves, upper arm, and head. He stood erect and moved in a deliberate manner.

Kama's visit had surprised Tukbaw, who admired the man's boldness. Tubkaw said he would never dare visit after celebrating only the initial and not yet the return covenant. Disa, an older woman in the household, chuckled because she had slept near Kama. He was not, she said, as fearless as he appeared. He had not slept during the night because he feared that his hosts would kill and behead him if he did so.

It would never do to leave the impression that Ilongots, by their own standards, never stumble as they manage their social relations. Even Kama, one of the more graceful among them, made Disa and her companions chuckle. At the same time, Kama's vigilance was a condition of his exceptional performance. Had he not been watchful (taikut), he would not have dared do as he did. Valued and cultivated qualities still are, at times, ambiguously realized in everyday life.

\title{
An Afflicted Man
}

Let me return for a moment to Brody's analysis of the Athabascan hunters. He characterizes the ways that hunting decisions (probably not the right word for such an ever-changing fluid process) unfold in this manner:

\begin{abstract}
Although the mode is still one of wait and see, at the end of the day, at the close of much slow and gentle talk about this and that, a strong feeling has arisen about the morning: we shall go to Bluestone, maybe as far as the cross. We shall look for trout as well as moose. A number of individuals agree that they will go. But come morning, nothing is ready. No one has made any practical, formal plans. As often as notindeed, more often than not-something quite new has drifted into conversations, other predictions have been tentatively reached, a new consensus appears to be forming. As it often seems, everyone has changed his mind. [1982: 36]
\end{abstract}

Perhaps a meander best describes the trajectory of such action. If the meander describes a pattern, it fails to characterize how human actors are purposive and take account of multiple human and natural factors. 
The ways people chart their courses involve complex judgments and intricate forms of human responsiveness and cooperation.

In a case in point, Tagu, a man long afflicted with tuberculosis, became acutely ill. A group of Ilongots and I hastened to see him, as I noted in my field journal:

\begin{abstract}
About 10:00 A.M. I went with Bayaw and Lakay to see Tagu. While I was there he got really, really sick: he was talking about whom he would give his things to; he said he was dying; he said he had no bad feelings about anybody there [in other words, after death his spirit would not return to afflict the living]. Lots and lots of people came. His brothers were in tears. They sent for another brother and sister because they were afraid he would die. Shelly came by and gave him a shot with shaking, trembling hands. It seemed to make him a little better. I was moved by the concern, the way they cared for him.
\end{abstract}

People told me that an Ifugao shaman who resided nearby was coming to perform a curing ritual. They spoke, at least to my ears, as if the ritual were going to start that day or the next.

It was not, however, until eleven days later that a young man came to tell me that the Ifugao shaman, in response to our request, had said that we could take notes but no pictures. Three days later, a full two weeks after I thought the shaman was on his way, the ceremony seemed close to beginning; I wrote the following in my field journal:

About 5:15 P.M. people began to arrive for the ceremony.... The expectation was that the ceremony would take place here, but then it turned out otherwise... Shortly after we ate, Ingal arrived and said the shaman was doing a ceremony downstream, so we had best go to sleep because he wouldn't be here until late.... We chatted a while and, very uncomfortable with the early hour, we went to bed about 7:30 P.M. - as we were going to sleep the house was a virtual hospital, with a skeletal Tagu, his brother with rheumatism, lots of people with colds. As we went to sleep, then, we felt pretty depressed: low, itchy, uncomfortable with the early hour, sad at the pervasive sense of illness. At 1:00 A.M. we were awakened. People arrived from downstream. The shaman had awakened them as he passed by; Tagu's brother had come by here to say that the shaman just passed by one house and went to another across the stream [where he would hold the ceremony] - the idea is that you treat a person at the place where he got sick.

My clock-bound frustration simply permeates the journal entry. Besides noting the time repeatedly, I feel discomfort with going to bed 
earlier than usual and depression brought on by the creeping, to me befuddling, pace of things.

The Ilongots themselves, of course, were mildly puzzled because the Ifugao practices were not fully known and because a shaman's performance, as part of its charisma, cultivates uncertainty and ambiguity. But the sense of frustration was much more mine than theirs.

The gradual unfolding, the multiple messages, the piece by piece revelation of when and where the ceremony would happen, gave the key participants an opportunity to prepare themselves for the shaman's intervention in a life-threatening crisis. Tagu did appear close to death. The shaman was expensive. The social support mobilized was extensive. The dangerous, afflicting spirit of Tagu's dead brother was invoked and felt to be present during the ceremony. In retrospect, it is little wonder that the event gathered itself together in bits and pieces, moving now forward, now backward. People needed time to collect themselves, both literally in one house, and by becoming oriented to a critical event where the stakes were high and the prognosis was uncertain.

\section{A Brother-in-Law's Arrival}

The anthropological literature could lead one to infer that the distinctive tempo of Ilongot visiting ends when the formal ritual begins. From this perspective it would seem that local versions of Indian Time fall by the wayside as formal procedures regulate the tempo of programmed ritual time (cf. R. Rosaldo 1985). In order to contest this widespread anthropological view, it is worth returning to an actual arrival scene marking the formal opening of a visit.

Recall that indigenous typifications made such arrivals appear formal, with a normal sequence of (1) silence, (2) betel quids and food, and (3) a request for news ("Are you people from there well?"). Contrast the typifications with the following actual arrival scene (recorded by Michelle Rosaldo) that took place when a group of visitors reached our household at about 4:30 P.M.

After about five minutes of relative silence, Bayaw, the male host, who was still lying down, said, "Give them a betel quid. I have no piper leaf." (Such commands, both here and in what follows, are called tuydek. They have been extensively studied in M. Rosaldo 1982.) 
The host's nephew began to prepare a quid, and then told a young male visitor, "Your areca nut now."

Tepeg, another male visitor, told Sawad, his sister and the female hostess, "Give me my pouch; give me the stuff for making a betel quid."

Sawad, in turn, told a child, "Give it to him, Lemmik."

A young male visitor told the host's nephew, "That tobacco of yours now."

The host's nephew told his aunt Sawad, "Give me your tobacco, aunt."

Two more minutes went by and Sawad told a young girl, "Ulling, go and fetch some water."

Then two people begin to talk.

The visitor Tepeg cursed in the general direction of his sister Sawad, the hostess.

As soon as Tepeg cursed, about ten minutes after the visitors' arrival, Sawad began to prepare a meal.

Although cultural typifications can make such arrivals appear routinized, they emerge in practice as a flow of tugs and pulls, requests and counter-requests, where tempo and grace are of the essence. Among other things, the casually reclining host was telling his brotherin-law not to stand on formality, indicating closeness verging on disrespect. The brother-in-law was making claims on his sister the hostess by being blunt and eventually cursing because he'd not been given a visitor's due: a betel quid and a meal.

This arrival scene's interpersonal content was manifest in such matters as timing and the directness or obliqueness of requests. Rather than being an end point for analysis, the formal sequence-silence, betel quid and meal, and request for news-served more as a background for understanding actual practices. The precise tempo and mode of unfolding reveal, both as reflection and ongoing negotiation, the quality of social relations among participants.

\section{Conclusion}

Writing about Algerian peasants, French sociologist Pierre Bourdieu has described the tempo and the politics of so-called reciprocity in terms so apt as to serve as a conclusion to this paper: 
When the unfolding of the action is heavily ritualized, as in the dialectic of offence and vengeance, there is still room for strategies which consist of playing on the time, or rather the tempo, of the action, by delaying revenge so as to prolong the threat of revenge. And this is true, $a$ fortiori, of all the less strictly regulated occasions which offer unlimited scope for strategies exploiting the possibilities offered by manipulation of the tempo of the action-holding back or putting off, maintaining suspense or expectation, or on the other hand, hurrying, hustling, surprising, and stealing a march, not to mention the art of ostentatiously giving time ("devoting one's time to someone") or withholding it ("no time to spare”). [Bourdieu 1977: 7]

Where Bourdieu and I, or most probably Algerian peasants and Philippine hunter-horticulturalists, diverge is in our descriptive aesthetics. His paradigm of challenge and response suggests the aesthetic of the marital arts. The Ilongots and I in following them would choose instead to emphasize social grace, the tempo and rhythms that shape the dance of life. My project has been to open the question of the differing aesthetics that shape the tempo of everyday life where clock-time is not the paramount reality.

\section{REFERENCES}

Bourdieu, Pierre. 1977. Outline of a Theory of Practice. Cambridge: Cambridge University Press.

Brody, Hugh. 1982. Maps and Dreams. New York: Pantheon.

Frake, Charles O. 1980a. “A Structural Description of Subanun 'Religious Behavior." In Frake, Language and Cultural Description. Stanford: Stanford University Press. Pp. 144-65.

- 1980b. "How to Enter a Yakan House." In Frake, Language and Cultural Description. Stanford: Stanford University Press. Pp. 214-32.

—. 1980c. "How to Ask for a Drink in Subanun." In Frake, Language and Cultural Description. Stanford: Stanford University Press. Pp. 166-73.

Philips, Susan. 1974. “Warm Springs 'Indian Time': How the Regulation of Participation Affects the Progression of Events." In Richard Bauman and Joel Sherzer, eds., Explorations in the Ethnography of Speaking. Cambridge: Cambridge University Press. Pp. 92-109.

Rosaldo, Michelle. 1980. Knowledge and Passion: Ilongot Notions of Self and Social Life. Cambridge: Cambridge University Press.

— 1982. "The Things We Do with Words: Ilongot Speech Acts and Speech Act Theory in Philosophy." Language and Society 2: 203-7. 


\section{Ilongot Visiting}

Rosaldo, Renato. 1980. Ilongot Headhunting, 1883-1974: A Study in Society and History. Stanford: Stanford University Press.

_. 1985. "While Making Other Plans." Southern California Law Review 58, 1: $19-28$.

- 1986. "Ilongot Hunting as Story and Experience." In Victor Turner and Edward Bruner, eds., The Anthropology of Experience. Urbana: University of Illinois Press. Pp. 97-138.

Thompson, E. P. 1967. “Time, Work-Discipline, and Industrial Capitalism." Past and Present 38: 56-97.

Weber, Max. 1958 [1904-5]. The Protestant Ethic and the Spirit of Capitalism. New York: Charles Scribner's Sons. 